Society of Edinburgh. Dr. Ellison is correspondent for solar activity of the British National Committee for the International Geophysical Year and has just been elected to succeed Dr. Y. Öhman, of Sweden, as international reporter for solar activity. After the death of Prof. W. M. H. Greaves and until the appointment of Prof. H. A. Brück as his successor (see Nature, 179, 454 ; 1957), Dr. Ellison served for nearly two years as acting director of the Royal Observatory, Edinburgh. He now succeeds Prof. Brück in the post at Dunsink.

\section{A Commonwealth Overseas Research Council}

LoRD HoMe, Secretary of State for Commonwealth Relations, announced at the Commonwealth Trade and Economic Conference in Montreal on September 24 that an Overseas Research Council is to be established to aid Commonwealth countries in scientific research. The United Kingdom Research Councils -Department of Scientific and Industrial Research, Medical Research Council and Agricultural Research Council-are willing, he said, to provide advice and assistance on research matters falling within their respective fields to any Commonwealth country requiring such assistance, wherever this can be done within the funds available. The Overseas Research Council will provide for the co-ordination of this assistance. It will advise Ministers on questions of co-operation in scientific research overseas and will also provide a central point to which Commonwealth Governments and research institutions can refer for advice and information.

The International Atomic Energy Agency : Scientific Advisory Committee

THE Board of Governors of the International Atomic Energy Agency has appointed the following to serve on the Agency's Scientific Advisory Committee : Prof. H. J. Bhabha (India) (subject to the concurrence of the Government of India) ; Sir John Cockcroft (United Kingdom); Prof. V. S. Emelyanov (U.S.S.R.) ; Prof. B. Goldschmidt (France) ; Prof. B. Gross (Brazil) ; Prof. W. B. Lewis (Canada) and Prof. I. I. Rabi (U.S.A.). The function of this Committee is to provide the Board and the DirectorGeneral of the Agency with advice on scientific and technical questions arising out of the Agency's programme. The members are appointed in their personal capacity, with the concurrence of their respective governments. Membership of the Committee is identical with that of the Scientific Advisory Committee of the United Nations, and it is expected that this fact will still further strengthen the relationship between the International Atomic Energy Agency and the United Nations.

\section{Nuclear Safety Advisory Committee}

IN moving the second reading of the Nuclear Installations (Licensing and Insurance) Bill in the House of Lords on November 13, the Minister of Power, Lord Mills, said that he and the Secretary of State for Scotland had decided to appoint a Nuclear Safety Advisory Committee composed of experts of the highest standing. They regarded such a Committee as necessary in view of the rapid strides which nuclear science and engineering were making and the consequent continuous evolution of the attendant problems of safety. In making appointments to the Committee, they intended to consult, inter alia, the Atomic Energy Authority, manufacturers of nuclear plant, the insurers, and the owners and operators of major nuclear installations. They had decided to establish this Committee administratively rather than by statute because developments in the industry were hard to foresee and might eventually necessitate changes in the constitution of the Committee or its terms of reference and such changes would thereby be more easily made. Referring to the exemption of the Atomic Energy Authority from licensing under the Bill, Lord Mills explained that the Authority's work was mainly experimental. To include it, apart from involving delays, would require a much larger inspectorate and also inspectors as expert in advanced research as the Authority's own scientists. Government departments would not normally be subject to licensing, but it was intended that they should follow the safety principles evolved between the Minister, the Atomic Energy Authority and the Nuclear Safety Committee and they would be under the same thirdparty liability as the Authority. Replying to ques. tions in the debate, Lord Mills added that the Bill did not cover the question of hospitals or the manufacture of pharmaceuticals, nor was it intended to cover ordinary university research or similar activities. If and when these activities required cover, fresh measures would be laid before Parliament.

\section{Moon Rocket Tracking}

A 108-mc./s. interferometer with a base line of 80 wave-lengths was used by the Royal Aircraft Establishment of the Ministry of Supply on November 8 to track the third American Moon rocket. A satisfactory record was obtained during 07.47-08.01 G.M.T., that is, for the time the rocket was above the horizon as seen from Great Britain. When the complete analysis is available the bearing of the rocket from Lasham, Hampshire, where the interferometer is located, will be known at every instant during this period with an accuracy of about 1 sec. of arc-an accuracy in position of approximately 10 miles at 4,000 miles range. Since the launching point is known, it should be possible to determine the complete orbit of the rocket, and by extrapolation to make a very fair estimate of the area where any surviving pieces may be. It is interesting to note that observers at Lasham realized at 07.55 that the missile had gone astray, since the type of record obtained was similar in character to those for the American Earth satellites. It is a feature of this equipment that a rapid assessment of the missile projectory is possible. The accuracy of bearing realizable with a fixed aerial equipment of this type is some hundred times greater than is possible with types of steerable aerials.

\section{Central Agency for Carbon-14 Determination}

DURING recent years, the study of primary production in the sea has been followed by radioactive tracer methods using carbon-14, a technique first employed by Nielsen. The method is very useful in that the field-work does not presuppose any expert knowledge of radiochemistry. On the other hand, manufacture of the necessary ampoules of sodium bicarbonate solution labelled with carbon-14, and the measurements of the radioactivity of the resulting filters, do require the facilities of a well-equipped radiochemical laboratory. In order to make such facilities available to the smaller marine laboratories, the recommendations adopted at the 1957 Bergen symposium on "Measurement of Primary Production in the Sea" have now been implemented and a central agency has been set up at Charlottenlund Slot, Denmark. This has been made possible by the 